\title{
Dominance, reproductive behaviours and female mate choice in sterilised versus non-sterilised invasive male crayfish
}

\author{
Nicky Green (D) - J. Robert Britton • Matt Bentley • Paul Stebbing • \\ Demetra Andreou
}

Received: 13 April 2020/Accepted: 19 June 2020/Published online: 8 July 2020

(C) The Author(s) 2020

\begin{abstract}
Many methods of controlling invasive crayfishes have limited success because they fail to target all life stages of the population, notably by capturing only large adults that can result in increased juvenile recruitment by removing intraspecific predation. An alternative approach uses the sterile male release technique that involves the mass release of sterile males into the environment, which then mate with fertile females, resulting in unfertilised eggs and, ultimately, reduced juvenile recruitment. This does, however, rely on the sterilised males exhibiting behaviours similar to non-sterilised (entire) males and remaining attractive to females during mate choice. Post-copulatory male guarding behaviour and female promiscuity might also be affected by male sterilisation. To test for the presence of normal
\end{abstract}

Handling Editor: Télesphore Sime-Ngando.

N. Green $(\varangle) \cdot$ J. R. Britton · D. Andreou

Department of Life and Environmental Sciences, Faculty of Science and Technology, Bournemouth University,

Fern Barrow, Poole, Dorset BH12 5BB, UK

e-mail: ngreen@bournemouth.ac.uk

M. Bentley

Newcastle University Singapore, SIT Building @

Nanyang Polytechnic, 172A Ang Mo Kio Avenue 8, \#05-

01, Singapore 567739, Singapore

P. Stebbing

APEM Ltd, A17 Embankment Business Park, Heaton

Mersey, Manchester SK4 3GN, UK reproductive behaviours in sterilised male American signal crayfish Pacifastacus leniusculus, a two-stage experiment examined how sterilisation affects female mate choice and promiscuity, male hierarchical status (relative dominance) and post-copulation guarding. Sterilised males showed similar reproductive behaviours to entire males and remained as attractive to females, with no differences in relative dominance. Post-copulation, guarding behaviours were also unaffected. Females did not display promiscuous behaviour and this was unaffected by whether males were entire or sterilised. The results demonstrated that sterilised males were equally as capable as entire males of achieving dominance and winning mates. In combination, these findings suggest that male sterilisation could be an effective control technique to help reduce juvenile recruitment in wild $P$. leniusculus populations by reducing reproductive success.

Keywords Biological invasion - Pacifastacus leniusculus $\cdot$ Sterile male release technique $\cdot$ Mate choice

\section{Introduction}

Biological invasions are recognised as a major threat to global biodiversity, with the capacity to disrupt ecosystem functioning (Simberloff et al. 2013; Gallardo et al. 2016). In freshwaters, alien crayfishes are 
among the most invasive taxa globally, having been spread around the world for reasons including aquaculture, human consumption and the aquarium trade (Capinha et al. 2011). They are also highly invasive, impacting entire ecosystems through the extirpation of native crayfishes via transmission of novel fungal pathogens, increased predation pressure on fishes and macro-invertebrates and physical changes to habitats (Jackson et al. 2016; Lodge et al. 2012; Twardochleb et al. 2013).

Populations of invasive crayfishes are thus subjected to regular management control programmes, where the methods used include mechanical and physical removal, biological control and biocide application (Gherardi et al. 2011; Stebbing et al. 2014). These control methods have the capacity to reduce crayfish abundance and enable the recovery of impacted fauna, but are usually effective only when applied over extended periods (Dana et al. 2010; Hein et al. 2007). Commonly used control methods, such as trapping, are frequently used over short time periods and tend to be size- and/or sex-biased, resulting in only a proportion of the population being targeted and removed (e.g. Freeman et al. 2009; Stebbing et al. 2014). As a result, there remains a requirement for the development of new methods that can inhibit the invasion of alien crayfishes and reduce their impacts without incurring high management costs and impacting non-target species (Hansen et al. 2013).

Autocidal approaches, including the sterile male release technique (SMRT), potentially provide effective control methods for invasive crayfishes (Gherardi et al. 2011; Stebbing et al. 2014). The SMRT involves the mass release of sterile males into the environment, which then mate with fertile females, resulting in low or negligible fertilisation rates, or the production of non-viable progeny (Knipling 1959). It has been used successfully on other taxa, such as in the control of insect pests (Takken et al. 1986) and invasive sea lamprey Petromyzon marinus. When applied to the latter in tributaries of Lake Superior between 1991 and 1999, a 59-86\% reduction in reproduction was achieved (Twohey et al. 2003). These methods generally require the use of either genetic manipulation or gamma irradiation to generate sterilised males.

The SMRT is considered to have potential for use on crayfish as their tendency to form population hierarchies results in dominant males potentially exerting a controlling influence on population growth, including the control of reproductive activities. It has the additional benefits of being an inversely densitydependent method that aims to reduce the number of juveniles, a life stage that is difficult to capture using other methods (Stebbing et al. 2014). Aquiloni et al. (2009) sterilised male Procambarus clarkii collected from the wild using irradiation and then returned them to the wild. Although successful in reducing the number of progeny by $43 \%$, this compared unfavourably to results achieved for insect species such as the tsetse fly Glossina palpalis in Nigeria, where the introduction of sterile males to a depleted population caused eradication (Takken et al. 1986). The irradiation procedure also has resource implications given the time and expense required to capture, transport, irradiate and return the crayfish, comparing unfavourably with control methods such as the use of biocides (Peay et al. 2018), although it is likely to be more effective than trapping alone (Stebbing et al. 2014). A potentially more practical and cost-effective method, as suggested by Stebbing and Rimmer (2014), is the functional sterilisation of the individuals via mechanical removal of the first and second pairs of pleopods (gonopods), theoretically rendering them incapable of mating effectively.

The effectiveness of SMRT is reliant on sterilised males exhibiting similar behaviours to non-sterilised males (Gherardi et al. 2011) and remaining attractive to females during mate choice. Regarding male behaviours, Stebbing and Rimmer (2014) reported no differences between the agonistic behaviours of sterilised and non-sterilised males, implying that male-male interactions would not be affected by sterilisation. Similarly, Johovic et al. (2019) found the removal of gonopods in Procambarus clarkii did not affect their ability to compete with untreated males for mates. Regarding mate choice, whilst females of some crayfish species prefer larger males (Aquiloni and Gherardi 2008), studies examining male dominance and female choice have produced mixed results. For example, Fero et al. (2007) detected no relationship between social status and mating in Faxonius rusticus, whereas Aquiloni et al. (2008) found female P. clarkii unable to recognise dominant males unless allowed to 'eavesdrop' on agonistic reactions. In addition, although crayfishes are assumed to have promiscuous mating systems (Kubec et al. 2018), female promiscuity has only been demonstrated in some species (e.g. Walker et al. 2002; Yue et al. 2010). The only known 
evidence for American signal crayfish Pacifastacus leniusculus being promiscuous, was recorded by Stebbing et al. (2003), who reported that, after mating, $45 \%$ of female P. leniusculus would move away from males that attempted to 'guard' them. Johovic et al. (2019) found sterilised male P. clarkii had to expend more effort to persuade promiscuous females to mate with them. Furthermore, in this study, copulations were shorter and more difficult to achieve by sterilised males, with this likely to relate to $P$. clarkii using internal fertilisation, the lack of gonopod-annulus ventralis contact being potentially problematic. Both of these findings suggest males sterilised via gonopod removal are less competitive than entire males (Johovic et al. 2019). Consequently, across invasive crayfish populations, there remains high uncertainty whether male sterilisation would alter their interactions with other males and affect reproductive behaviours in both sexes. This knowledge gap remains a major constraint in the application of SMRT for the management of invasive crayfishes in the wild.

The present study is a trial of mechanical sterilisation via the physical removal of the adult male gonopods in P. leniusculus. Mechanical sterilisation reduces the ability of the male to accurately place his spermatophore on the ventral surface of the female, thereby reducing the number of ova that can be fertilised. As there is little knowledge on the effects of this change to the physical state of the animal in relation to reproductive and hierarchical behaviour in $P$. leniusculus, the aim here was to overcome this by experimentally testing, in ex situ conditions, how male sterilisation affects their reproduction through testing its effect on male hierarchical status, female mate choice and promiscuity, and then post-copulation guarding. The null hypothesis tested was that reproductive behaviours of both sexes, and male hierarchical status, were not altered by male sterilisation.

\section{Methods}

Using P. leniusculus, two sets of experiments were completed: the first set tested male dominance and guarding, and female promiscuity, and the second set tested female mate choice. Dominance, guarding and promiscuity experiments took place in September and October 2018, whilst female choice experiments were carried out in 2017 and 2018.
Experimental animals

Adult male and female P. leniusculus, for use in the experiments, were collected using baited funnel traps from two adjacent fishing ponds located in Southern England in September 2017 and September 2018. In each year, 200 crayfish $(100 \mathrm{M}$ and $100 \mathrm{~F})$ were collected. The size (carapace length) of males ranged from $40 \mathrm{~mm}$ to $56 \mathrm{~mm}$, and $38 \mathrm{~mm}$ to $46 \mathrm{~mm}$ for females. In both years, $\approx 50 \%$ of males were sterilised upon capture via removal of the gonopods by either cutting them off with scissors (Stebbing and Rimmer 2014) or pulling them out using a pair of tweezers, with the sterilised/non-sterilised groups being size matched to ensure the groups were of similar carapace lengths. Only crayfish with both chelae intact were kept, although owing to a shortage of adult males, some did have unevenly sized or relatively small chelae in relation to their body size.

On arrival at the laboratory, all crayfish were placed individually into one of five sections within $90 \times 30 \times 30 \mathrm{~cm}(80 \mathrm{~L})$ glass tanks. Each section was divided using an opaque plastic partition with a small grille of 2-mm wire mesh at low level $(25 \mathrm{~mm}$ from bottom of tank) to allow water circulation. Water temperature was initially maintained at $14^{\circ} \mathrm{C}$ (to match the field site) with light on a 12:12 h light:dark cycle. Each section (16 L) contained a $20 \mathrm{~mm}$ layer of gravel and a shelter made from 50-mm-diameter plastic pipe. The divided tanks were set up in threetiered flow-through filtration systems, with each system housing 15 crayfish (five per tank). Water was pumped to the topmost tier and then circulated down through the two lower tanks and finally through a filter at ground level. Sterilised males, non-sterilised males and females were housed in different systems, thereby preventing accidental physical contact or semiochemical interaction between individuals of different treatment groups prior to the experiments. The crayfish were fed a diet of fresh carrot twice weekly.

Following a four-day acclimation period in the laboratory, all crayfish carapace lengths were recorded, and for males, chelae length was measured and any abnormalities were recorded. Each individual was given an identifying number (via permanent marker pen on the carapace) that was colour-coded in accordance with sex and sterilisation status. In 2017, temperature was reduced from $( \pm \mathrm{SE}) 14^{\circ} \mathrm{C}$ to 
$11{ }^{\circ} \mathrm{C} \pm 0.5{ }^{\circ} \mathrm{C}$, the temperature at which P. leniusculus mate in the UK, in $1{ }^{\circ} \mathrm{C}$ daily increments over a period of 3 days. In 2018, temperature was maintained at ambient levels $\left(14{ }^{\circ} \mathrm{C} \pm 0.5^{\circ} \mathrm{C}\right)$ due to the chillers no longer being able to reduce the temperatures any further. For the female choice experiments, males were fitted with a tethering loop a minimum of $24 \mathrm{~h}$ prior to being used in an experiment. For this, a hole was made through the central uropod using a sterile needle, then a short length of light-gauge fishing line was threaded through and tied into a loop of approximately $10 \mathrm{~mm}$ diameter. Sterilised and non-sterilised males were captured from separate ponds in order to prevent the pairing of males with prior contact experience and therefore potential hierarchical effects.

For experiments, sterilised and non-sterilised males were paired according to carapace and chelae length, with a maximum difference of $2 \mathrm{~mm}$ in either characteristic to minimise any size effects. Crayfish with unevenly or unusually sized claws were matched with males with similar attributes in order to prevent any competitive advantage. Females were selected to be a similar size or slightly smaller than the males. Animals in moult or that did not appear to be in good condition were not used.

All subsequent analyses on experimental data were completed using SPSS version 23.0 (IBM 2017). Where error values are presented around means, they represent standard error unless stated. Significance is reported as exact two-tailed unless stated. All data were nonparametric.

Experimental design, data capture and analysis

The set of experiments initially compared sterilised and non-sterilised males' ability to achieve dominance in an agonistic encounter and to generate dominant and subordinate individuals for the subsequent female choice experiments (2018 only). Here, a female was allowed to choose between a sterilised and nonsterilised male. When mating occurred, guarding and promiscuity were tested via the introduction of a new male, post-copulation.

All experiments were conducted in a $900 \times 300 \mathrm{~mm}$ tank on a flow-through system (as described above). The water temperature in the experimental tanks also differed between the 2 years (11.0 $\pm 0.5{ }^{\circ} \mathrm{C}$ in $2017 ; 14.0 \pm 0.5{ }^{\circ} \mathrm{C}$ in 2018). All experiments were completed in darkness (between
19.00 and $00.00 \mathrm{~h}$ ), the time when crayfish are normally most active (Franke and Hörstgen-Schwark 2015). The nature of the experiments meant that the males used in individual dominance trials were then reused in female choice trials; the latter took place after a minimum of $24 \mathrm{~h}$ and a maximum of 17 days $[$ mean $=12.3 \pm 5.8$ days (SD) $]$ after the dominance trial. The only illumination was above the tanks to allow filming; this comprised two battery-operated 'stick-on' lights positioned $30 \mathrm{~cm}$ above the tank in 2017 and LED aquarium lights in 2018. Filming was conducted using a Go-Pro Hero 3 video camera suspended $30 \mathrm{~cm}$ above the tank.

The basis for the analysis of the dominance, guarding and promiscuity experiments was a fight ethogram adapted from Bruski and Dunham (1987) by Bergman and Moore (2003). This categorised the different aspects of agonistic behaviour (Table 1) and enabled each animal to be scored by multiplying the length of time (s) spent displaying each behaviour with the score for that behavioural category. For guarding and promiscuity, the ethogram was modified to include relevant behaviours such as sexual activity.

Male dominance

There were 26 male dominance trials completed and analysed. One sterilised male and one non-sterilised male were placed at each end of the tank, being separated by an opaque plastic partition placed half way along its length and extending to the top of the tank. Following an acclimatisation period (10 min), the partition was removed and the behaviour of both males filmed (15 min). The starting position in the tank (left/right) was alternated for the two categories of male to avoid positional bias. The males were not tethered during this experiment, and the fitted tethering loop was considered unlikely to interfere with normal behaviour as the animals had become accustomed to its presence, plus any disturbance effect would be equal as both animals had tethers. In the analyses, an encounter was deemed to have started when one crayfish approached another and ended when the crayfish moved more than one body length away and reverted to behavioural intensity level 0 (Table 1). The frequency and intensity of each behaviour was multiplied together to give each male a dominance score in accordance with the fight ethogram. These data were then tested between using 
Table 1 Fight and behavioural ethogram codes used in the experiments, as devised by Bruski and Dunham (1987) and adapted by Bergman and Moore (2003)

\begin{tabular}{|c|c|c|}
\hline $\begin{array}{l}\text { Intensity } \\
\text { level }\end{array}$ & Fight behaviour description & Guarding behaviour description \\
\hline-2 & Tailflip away from opponent or fast retreat & Tailflip away from opponent or fast retreat \\
\hline-1 & Slowly back away from opponent & Slowly back away from opponent \\
\hline 0 & Ignore opponent with no response or threat display & Ignore opponent with no response or threat display \\
\hline 1 & Approach without a threat display & $\begin{array}{l}\text { Approach without a threat display/mate positions himself } \\
\text { within one body length of female }\end{array}$ \\
\hline 2 & $\begin{array}{l}\text { Approach with threat display using meral spread and/or } \\
\text { antennal whip }\end{array}$ & $\begin{array}{l}\text { Approach with threat display using meral spread and/or } \\
\text { antennal whip }\end{array}$ \\
\hline 3 & $\begin{array}{l}\text { Initial claw use by boxing, pushing or touching with } \\
\text { closed claws }\end{array}$ & $\begin{array}{l}\text { Initial claw use by boxing, pushing or touching with closed } \\
\text { claws }\end{array}$ \\
\hline 4 & Active claw use by grabbing opponent with open claws & Active claw use by grabbing opponent with open claws \\
\hline 5 & $\begin{array}{l}\text { Unrestrained fighting by grabbing opponents claws or } \\
\text { appendages }\end{array}$ & $\begin{array}{l}\text { Intervention: mate actively attempts to remove challenger } \\
\text { from contact with female }\end{array}$ \\
\hline
\end{tabular}

a Mann-Whitney U test using the dominance score as the test variable and sterilised or non-sterilised ( $\mathrm{S}$ or M) as the grouping variable. Position in arena (left or right side) was tested in the same way in order to ascertain positional bias. The distribution of sterilised and non-sterilised males as dominance contest winners was tested for goodness of fit using a Chi-squared test $\left(\chi^{2}\right)$.

Female choice experiment

In this experiment, one sterilised and one nonsterilised male were tethered and placed into equalsized arenas delineated by a clear Perspex partition (enabling the female to have sight of both males) secured half way across the width of the tank (at $150 \mathrm{~mm}$ ), extending for $300 \mathrm{~mm}$ into the tank and being $300 \mathrm{~mm}$ high (Fig. 1). In 2018, the same pairs used in the previous dominance experiments were selected, meaning the relative dominance status of each male was known prior to the experiment. Each male was tethered by attaching the loop through the uropod to a $500 \mathrm{~g}$ fishing weight via a metal clip (in 2017) or a safety pin (in 2018) and length of fishing line, the length of line being sufficient to maintain them within the area delineated by the partition and prevent them from interacting with each other. The relative position of the two categories of male was alternated between experiments in order to prevent left-right bias.
The males were allowed to acclimatise $(10 \mathrm{~min})$ prior to the introduction of the female at the opposite end of the tank (Fig. 1). Interactions between the three individuals were filmed either until mating took place or for $30 \mathrm{~min}$ in the absence of mating. Videos where mating did not occur within $30 \mathrm{~min}$ were discarded. A nominal 'territory' for each male covering two-thirds of their half of the tank was devised for video analysis purposes (Fig. 1). The videos were subsequently analysed to record the amount of time the female spent in the 'territory' of each male (Fig. 1), recorded as starting when half of the female's carapace crossed the line. To ensure that the female had the opportunity to make a choice, only videos where the female had sight of both males prior to copulation were analysed. A total of 50 trials were completed, of which 28 resulted in copulation between the female and one of the males. However, of these 28 copulations, 9 were considered as not being appropriate for analysis as the female appeared not to have sight of both males prior

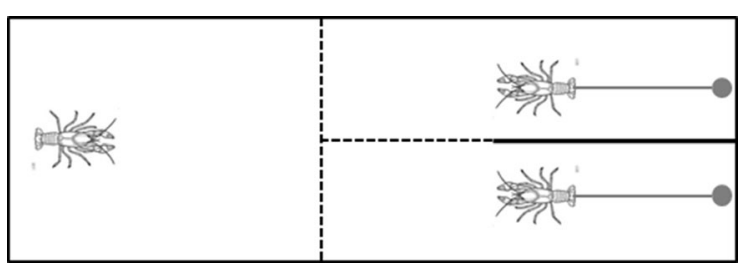

Fig. 1 Design of experimental arena: right: tethered males, left: position of female on introduction. Dashed lines represent the 'territory' of each male as used in video analysis 
to the start of copulation or the video was not of sufficient quality for analysis, reducing the sample size to 19 (9 in 2017, 10 in 2018).

The total time spent by the female in the territory of each male was expressed as the percentage of total interaction time, i.e. of total time spent in their territory. Owing to the differences in temperature between 2017 and 2018, the data were tested for difference between years using a Mann-Whitney ' $U$ ' Test. These differences were not significant ( $\mathrm{U}=180.0 ; P=1.0$ ) so the data were combined to enable a single test. The mate choice by the female (sterilised or non-sterilised) and (in 2018) the dominance status of males (dominant or subordinate) were tested using a Chi-squared goodness-of-fit test.

Post-copulatory guarding experiment

When copulation occurred in the previous experiment, the mated pair were moved post-copulation to a separate $900 \times 300 \mathrm{~m}$ tank containing two shelters to minimise stress. After 5 min, a new male of haphazardly chosen size and sterilisation status was introduced and the interaction between the three animals filmed for up to $10 \mathrm{~min}$. The original mate was classified as the 'mate', whilst the new male was the 'challenger'. The videos generated were analysed by categorising the different aspects of agonistic and guarding behaviour using the modified version of the fight ethogram (Table 1). Due to video recording issues, a total of 11 trials were analysed for postcopulatory guarding.

The frequency [as time (s)] and intensity of each recorded behaviour was multiplied together for mate and challenger, giving them a 'guarding' score. As the resulting data had high variance, they were $\log$ transformed then tested for differences between 'mate' and 'challenger' scores using a Mann-Whitney $\mathrm{U}$ Test. Additionally the animals with the highest scores in each bout were tested against their sterilisation status using Mann-Whitney U and Chi-squared goodness-of-fit tests.

\section{Promiscuity experiment}

At the end of the guarding experiment, the original mate was removed and interactions between the female and male challenger were filmed for up to $10 \mathrm{~min}$. Ten experiments were completed, one being discontinued as the male's attempts to copulate risked harming the female. The videos were analysed using the 'willingness ethogram' modified from the fight ethogram used in the dominance and guarding experiments (Table 2, modifications marked with*). The frequency and intensity of each behaviour were multiplied together to generate a 'willingness score' for each male and female. The difference in willingness scores between males (challengers) and females, and between sterilised and non-sterilised males, was tested using Mann-Whitney $\mathrm{U}$ and Chi-squared goodness-of-fit tests.

\section{Results}

There were no significant differences in dominance scores between sterilised and non-sterilised males, with the mean dominance score of sterilised males ( $\mathrm{n}=26$ ) being $912.0 \pm 819.3$ and non-sterilised males $(\mathrm{n}=26$ ) being $952.8 \pm 797.2$ (Mann-Whitney: $\mathrm{U}=327.0, P=0.84)$. Differences between dominance score and starting position of the crayfish in the tank were also not significant (Mann-Whitney: $\mathrm{U}=335.0, P=0.96)$.

Of the 19 copulations analysed for female mate choice, 10 were with non-sterilised males and 9 with sterilised males, with the difference not being significant $\left(\chi^{2}=0.11 ; P=0.75\right)$. In 2018 , where male dominance was also quantified $(\mathrm{n}=10)$, female mate choice was not significantly related to male dominance status $\left(\chi^{2}=0.11 ; P=0.74\right)$. Regarding post-copulatory guarding, mates were found to have higher mean guarding scores than challengers $(1106 \pm 609$ vs. $792 \pm 473$ ), but with these differences not significant (Mann-Whitney: $U=44.0 ; P=0.29$ ). Additionally, there were no differences between the guarding scores of sterilised and non-sterilised males (Mann-Whitney: $\mathrm{U}=44.0 ; P=0.34$ ).

For promiscuity, the data revealed males had higher mean willingness scores than females $(875 \pm 1058$ vs. $256 \pm 856$ ), with the difference between the sexes being significant (Mann-Whitney: $\quad U=17.0$; $P=0.01)$, implying that females were unwilling to mate a second time. No significant differences between the willingness scores of sterilised and nonsterilised males $(\mathrm{U}=8.0 ; P=0.44)$ and of females mated with sterilised or non-sterilised males $(\mathrm{U}=4.0$; $P=0.14$ ) were found. 
Table 2 Willingness ethogram codes adapted from Bruski and Dunham (1987) by Bergman and Moore (2003)

\begin{tabular}{ll}
\hline Intensity level & Description \\
\hline-5 & Female resists copulation by tucking tail into abdomen* \\
-2 & Tailflip away from opponent or fast retreat \\
-1 & Slowly back away from opponent \\
0 & Ignore opponent with no response or threat display \\
1 & Approach without a threat display \\
2 & Approach with threat display using meral spread and/or antennal whip \\
3 & Initial claw use by boxing, pushing or touching with closed claws \\
4 & Turning of female by male/female allows turning* \\
5 & Mating* \\
\hline
\end{tabular}

\section{Discussion}

The results infer that sterilised male P. leniusculus do not differ from non-sterilised males in their ability to achieve dominance and successfully compete for mates, thus rejecting the null hypothesis. This provides evidence that the use of sterilised males as a $P$. leniusculus management technique could lead to a measurable decrease in juvenile recruitment, leading to reductions in population abundance.

The female choice experiments suggested that mate choice was not related to either sterilisation or dominance status. The actual mechanisms that influence female mate choice within these experiments are unclear. As dominance status was predetermined, it was possible that $P$. leniusculus females were unable to recognise dominance status without eavesdropping on contests (in concurrence with Aquiloni et al. 2008), bearing in mind that the males were tethered and therefore unable to display dominant/submissive behaviour. The female choice experiments assumed a requirement for visual recognition (i.e. the female having sight of both males) prior to a female being considered as 'choosing' a mate, but the role of semiochemicals in the choice process was not considered (Berry and Breithaupt 2010). Aquiloni et al. (2008) found female P. clarkii unable to recognise dominance by sight or smell; however, others have found that crayfishes can recognise dominance status semiochemically (e.g. Zulandt-Schneider et al. 1999; Bergman et al. 2003). During our study, when dominance experiments were repeated, males that had previously encountered each other then avoided contact. This suggests that dominant/subordinate status was determined in their previous encounter, implying that each individual recognised the other via semiochemical signals (Kubec et al. 2018). The role of semiochemicals may also affect the copulation process. For example, Johovic et al. (2019) found that sterilised males engaged in longer and more frequent pre-copulatory agonistic interactions with females than untreated males, and speculated that gonopod removal caused a higher aggressive state where treated males released higher levels of urine-borne semiochemicals. In a wild situation, females would be likely to avoid such males in order to prevent injury (Berry 2008). These experiments took place in tanks with a circulating water supply that would have contained semiochemicals from several males and females. Therefore, it is likely both females and males would have difficulties attributing any semiochemicals released to a specific individual under such conditions, but their agonistic and copulatory behaviours may have been affected by the presence of such chemicals (Johovic et al. 2019). It would have been beneficial to change the water between experiments in order to allow further investigations of semiochemical-related influences on copulation (Berry and Breithaupt 2010; Stebbing et al. 2003) and their relevance to the application of male sterilisation.

Fewer copulations occurred in 2018 (14 of 30) compared to 2017 (14 of 20); conditions in the collection and maintenance of animals as well as experimental design were identical for both years, other than some differences in ambient water temperature and light intensity. Although both of these factors could have influenced the results, there were no significant behavioural differences in the experimental results across both years. The females could not be acclimatised in the experimental arena prior to the experiment and could have been stressed by the higher light levels; additionally, as P. leniusculus are reported 
to mate between $10{ }^{\circ} \mathrm{C}$ and $12{ }^{\circ} \mathrm{C}$ (Guan and Wiles 1999), the higher temperature in $2018\left(14 \pm 0.5^{\circ} \mathrm{C}\right.$ vs. $11 \pm 0.5^{\circ} \mathrm{C}$ ) could have affected their behaviour. It is therefore recommended that future work is performed at the lower temperatures and also uses infrared lighting/camera systems where possible (e.g. Fero et al. 2007) to reduce light-related stress.

Although not supported statistically, direct observations suggest that male $P$. leniusculus will readily guard the female following copulation, with the lack of significant differences detected in experiments potentially being an artefact of the ethogram design and/or the relatively small sample size $(\mathrm{N}=11)$. In addition, post-copulatory guarding could be less likely to occur in a wild situation as the mate, challenger and female all have greater opportunities to avoid the type of relatively intense encounters that occurred under the experimental conditions (Bergman and Moore 2003). Males may be more successful at guarding females post-copulation without the intrusion of a challenger, whereas females could be more able to escape the attentions of her mate and avoid being guarded.

The results also suggest that female $P$. leniusculus did not display promiscuous behaviour, and this behaviour was not influenced by the sterilisation status of the male. Although the experiments took place only a short time $(10 \mathrm{~min})$ after the original mating, it is possible that females would seek to mate again hours or possibly days later. However, this is considered unlikely because spawning in P. leniusculus generally takes place soon after mating (Vogt 2016). The lack of promiscuous behaviour in $P$. leniusculus supports the potential efficacy of the male sterilisation technique because it implies that wild females are unlikely to seek multiple partners, and as such, following mating with a sterile male, females are considered unlikely to subsequently mate with an entire male. It also implies that females did not find copulation with a sterilised male sufficiently unsatisfactory to then seek new mates. In P. clarkii, which is known to be promiscuous (Yue et al. 2010), gonopod removal resulted in shorter and less efficient copulations (Johovic et al. 2019), with speculation that both sexes would be aware of such inefficiencies due to their internal mating system, but only 1 of 14 females compensated by mating for a second time. Although our experimental sample size was relatively small $(\mathrm{N}=10)$, the observed behaviours were exhibited under conditions when the females were unable to escape the attentions of the male. In a wild situation, avoidance of additional suitors by the female is more likely to be achievable given that the opportunities for the female to take shelter and avoid such encounters would be higher (Bergman and Moore 2003). Consequently, in a population control scenario, decreasing fecundity could be initiated once a relatively small proportion of the adult male population has been sterilised (Stebbing and Rimmer 2014). The technique thus has the potential to compare favourably with other methods in terms of resource use, as it would shorten the period of time where intensive trapping would be required. For example, Stebbing et al. (2016) used a population model to simulate various control scenarios and found eradication would be achieved quicker when combining trapping and sterilisation than with trapping alone. The method also compares favourably with techniques such as biocide application which have high environmental as well as financial costs (Peay et al. 2019) and dewatering which is not a feasible method in many water bodies (Peay and Dunn 2014).

To conclude, the tests undertaken in the present study demonstrated that sterilised males are equally capable of achieving dominance and winning mates as entire males. Furthermore, this research has found further evidence that $P$. leniusculus males, regardless of their sterilisation status, will guard their mates postcopulation, and that females are generally not promiscuous. It is possible that the behaviours observed in the present laboratory study are likely to be magnified in the wild situation due to the ability of individual crayfish to disperse away from agonistic encounters, guarding scenarios and pursuing suitors. The combination of these findings suggests that male sterilisation has potential to be a successful technique in helping control invasive populations of $P$. leniusculus through reducing juvenile recruitment.

Open Access This article is licensed under a Creative Commons Attribution 4.0 International License, which permits use, sharing, adaptation, distribution and reproduction in any medium or format, as long as you give appropriate credit to the original author(s) and the source, provide a link to the Creative Commons licence, and indicate if changes were made. The images or other third party material in this article are included in the article's Creative Commons licence, unless indicated otherwise in a credit line to the material. If material is not included in the article's Creative Commons licence and your intended use is not permitted by statutory regulation or exceeds 
the permitted use, you will need to obtain permission directly from the copyright holder. To view a copy of this licence, visit http://creativecommons.org/licenses/by/4.0/.

\section{References}

Aquiloni L, Gherardi F (2008) Mutual mate choice in crayfish: large body size is selected by both sexes, virginity by males only. J Zool 274:171-179

Aquiloni L, Buric M, Gherardi F (2008) Crayfish females eavesdrop on fighting males before choosing the dominant mate. Curr Biol 18:462-463

Aquiloni L, Becciolini A, Berti R, Porciani S, Trunfio C, Gherardi F (2009) Managing invasive crayfish: use of X-ray sterilisation of males. Freshw Biol 54:1510-1519

Bergman D, Moore P (2003) Field observations of intraspecific agonistic behavior of two crayfish species, Orconectes rusticus and Orconectes virilis, in different habitats. Biol Bull 205:26-35

Bergman D, Kozlowski C, McIntyre J, Huber R, Daws A (2003) Temporal dynamics and communication of winner-effects in the crayfish, Orconectes rusticus. Behaviour 140:805-825

Berry F (2008) The behavioural function of pheromones in crayfish. Diss. University of Hull

Berry F, Breithaupt T (2010) To signal or not to signal? Chemical communication by urine-borne signals mirrors sexual conflict in crayfish. BMC Biol 8:25

Bruski C, Dunham D (1987) The importance of vision in agonistic communication of the crayfish Orconectes rusticus. Behaviour 103:83-107

Capinha C, Leung B, Anastácio P (2011) Predicting worldwide invasiveness for four major problematic decapods: an evaluation of using different calibration sets. Ecography 34:448-459

Dana ED, López-Santiago J, García-de-Loma J, García-Ocaña DM, Gámez V, Ortega F (2010) Long-term management of the invasive Pacifastacus leniusculus (Dana, 1852) in a small mountain stream. Aquat Invasions 5:317

Fero K, Simon JL, Jourdie V, Moore PA (2007) Consequences of social dominance on crayfish resource use. Behaviour 144(1):61-82

Franke R, Hörstgen-Schwark G (2015) Control of activity patterns in crowded groups of male noble crayfish Astacus astacus (Crustacea, Astacidea) by light regimes: a way to increase the efficiency of crayfish production? Aquaculture 446:103-110

Freeman M, Turnbull J, Yeomans W, Bean C (2009) Prospects for management strategies of invasive crayfish with an emphasis on biological control. Aquat Conserv 20:211-233

Gallardo B, Clavero M, Sánchez M, Vilà M (2016) Global ecological impacts of invasive species in aquatic ecosystems. Glob Change Biol 22:151-163

Gherardi F, Aquiloni L, Diéguez-Uribeondo J, Tricarico E (2011) Managing invasive crayfish: is there a hope? Aquat Sci 73:185-200

Guan R, Wiles P (1999) Growth and reproduction of the introduced crayfish Pacifastacus leniusculus in a British lowland river. Fish Res 42:245-259
Hansen G, Hein C, Roth B, Vander Zanden J, Gaeta J, Latzka A (2013) Food web consequences of long term crayfish control. Can J Fish Aquat Sci 70:1109-1122

Hein C, Vander Zanden J, Magnuson J (2007) Intensive trapping and fish predation cause massive population decline of an invasive crayfish. Freshwater Biol 52:1134-1146

IBM (2017) SPSS statistics 23. https://www.ibm.com/analytics/ us/en/technology/spss/

Jackson M, Miller K, Britton JR, Donohue I (2016) Dietary niche constriction when invaders meet natives: evidence from freshwater decapods. J Anim Ecol 85:1098-1107

Johović I, Verrucchi C, Inghilesi AF, Scapini F, Tricarico E (2019) Managing the invasive crayfish Procambarus clarkii: is manual sterilisation the solution? Freshw Biol 65:621-631

Knipling E (1959) Sterile-male method of population control. Science 130:902-904

Kubec J, Kouba A, Buřič M (2018) Communication, behaviour, and decision making in crayfish: a review. Zoologischer Anzeiger 278:28-37

Lodge D, Deines A, Gherardi F et al (2012) Global Introductions of crayfishes: evaluating the impact of species invasions on ecosystem services. Ann Rev Ecol Evol Syst 43:449-472

Peay S, Dunn A (2014) The behavioural response of the invasive signal crayfish Pacifastacus leniusculus to experimental dewatering of burrows and its implications for eradication treatment and management of ponds with crayfish. Ethol Ecol Evol 26(2-3):277-298

Peay S, Johnsen SI, Bean CW, Dunn AM, Sandodden R, Edsman L (2019) Biocide treatment of invasive signal crayfish: successes, failures and lessons learned. Diversity 11(3):29

Schneider R, Schneider R, Moore P (1999) Recognition of dominance status by chemoreception in the red swamp crayfish, Procambarus clarkii. J Chem Ecol 25:781-794

Simberloff D, Martin J, Genovesi P et al (2013) Impacts of biological invasions: what's what and the way forward. Trend Ecol Evol 28:58-66

Stebbing P, Rimmer G (2014) C5777 male crayfish sterilisation study Report.pdf. Centre for the Environment, Fisheries, Aquaculture Science, Weymouth, UK

Stebbing P, Bentley M, Watson G (2003) Mating behaviour and evidence for a female released courtship pheromone in the signal crayfish Pacifastacus leniusculus. J Chem Ecol 29:465-475

Stebbing P, Longshaw M, Scott A (2014) Review of methods for the management of non-indigenous crayfish, with particular reference to Great Britain. Ethol Ecol Evol 26:204-231

Stebbing P, McPherson N, Ryder D, Jeffery K (2016) Controlling invasive crayfish: managing signal crayfish populations in small enclosed water bodies.pdf. Centre for the Environment, Fisheries, Aquaculture Science, Weymouth, UK

Takken V, Oladunmade MA, Dengwat L, Feldmann HU, Onah JA, Tenabe SO, Hamann HJ (1986) The eradication of Glossina palpalis (Robineau-Desvoidy) (Diptera: Glossinidae) using traps, insecticide-impregnated targets and the sterile insect technique in central Nigeria. Bull Entomol Res 76:275-286

Twardochleb L, Olden J, Larson E (2013) Global meta-analysis of the ecological impacts of non-native crayfish. Freshw Sci 32:1367-1382 
Twohey MB, Heinrich JW, Seelye JG, Fredricks KT, Bergstedt RA, Kaye CA, Scholefield RJ, McDonald RB, Christie GC (2003) The sterile-male-release technique in Great Lakes sea lamprey management. J Great Lakes Res 29:410-423

Vogt G (2016) Fate of glair glands and oocytes in unmated crayfish: a comparison between gonochoristic slough crayfish and parthenogenetic marbled crayfish. bioRxiv 047654. https://doi.org/10.1101/047654

Walker D, Porter BA, Avise J (2002) Genetic parentage assessment in the crayfish Orconectes placidus, a high fecundity invertebrate with extended maternal brood care. MolecEcol 11:2115-2122

Yue GH, Li JL, Wang CM, Xia JH, Wang G, Feng JB (2010) High prevalence of multiple paternity in the invasive crayfish species, Procambarus clarkii. Int J Biol Sci 6:107-115

Publisher's Note Springer Nature remains neutral with regard to jurisdictional claims in published maps and institutional affiliations. 